\title{
cDNA microarray analysis of the effect of cantharidin on DNA damage, cell cycle and apoptosis-associated gene expression in NCI-H460 human lung cancer cells in vitro
}

\author{
TE-CHUN HSIA ${ }^{1,2}$, CHIEN-CHIH YU ${ }^{3}$, SHU-CHUN HSU ${ }^{4}$, NOU-YING TANG ${ }^{1}$, HSU-FENG LU ${ }^{5}$, \\ CHUN-SHU YU ${ }^{3}$, SHIN-HWAR WU ${ }^{6}$, JAUNG-GENG LIN ${ }^{1}$ and JING-GUNG CHUNG ${ }^{4,7}$ \\ ${ }^{1}$ Graduate Institute of Chinese Medicine, China Medical University; ${ }^{2}$ Department of Internal Medicine, \\ China Medical University Hospital; ${ }^{3}$ School of Pharmacy, China Medical University; \\ ${ }^{4}$ Department of Biological Science and Technology, China Medical University, Taichung 40402; \\ ${ }^{5}$ Department of Clinical Pathology, Cheng Hsin General Hospital, Taipei 11220; ${ }^{6}$ Division of Critical Care Medicine, \\ Department of Medicine, Changhua Christian Hospital, Changhua 50006; ${ }^{7}$ Department of Biotechnology, \\ Asia University, Taichung 41354, Taiwan, R.O.C.
}

Received March 5, 2014; Accepted February 17, 2015

DOI: $10.3892 / \mathrm{mmr} .2015 .3538$

\begin{abstract}
Cantharidin (CTD) induces cytotoxic effects in different types of human cancer cell; however, to date, there have been no studies on the effects of CTD on gene expression in human lung cancer cells and the potential associated signaling pathways. Therefore, the present study aimed to investigate how CTD affects the expression of key genes and functional pathways of human H460 lung cancer cells using complementary DNA microarray analysis. Human H460 lung cancer cells were cultured for $24 \mathrm{~h}$ in the presence or absence of $10 \mu \mathrm{M} \mathrm{CTD}$; gene expression was then examined using microarray analysis. The results indicated that 8 genes were upregulated $>4$-fold, 29 genes were upregulated $>3$-4-fold and 156 genes were upregulated $>2$-3-fold. In addition, 1 gene was downregulated $>4$ fold, 14 genes were downregulated $>3$-4-fold and 150 genes were downregulated $>2-3$ fold in $\mathrm{H} 460$ cells following exposure to CTD. It was found that CTD affected DNA damage genes, including DNIT3 and GADD45A, which were upregulated 2.26- and 2.60-fold, respectively, as well as DdiT4, which was downregulated 3.14-fold. In addition, the expression of genes associated with the cell cycle progression were altered, including CCND2, CDKL3 and RASA4, which were upregulated 2.72-,
\end{abstract}

Correspondence to: Dr Jing-Gung Chung, Department of Biological Science and Technology, China Medical University, 91 Hsueh-Shih Road, Taichung 40402, Taiwan R.O.C.

E-mail: jgchung@mail.cmu.edu.tw

Professor Jaung-Geng Lin, Graduate Institute of Chinese Medicine, China Medical University, 91 Hsueh-Shih Road, Taichung 40402, Taiwan R.O.C.

E-mail: jglin@mail.cmu.edu.tw

Key words: cantharidin, H460 cells, DNA damage, cell cycle, apoptosis, in vitro
2.19- and 2.72-fold, respectively; however, CDC42EP3 was downregulated 2.16-fold. Furthermore, apoptosis-associated genes were differentially expressed, including CARD6, which was upregulated 3.54-fold. In conclusion, the present study demonstrated that CTD affected the expression of genes associated with DNA damage, cell cycle progression and apoptotic cell death in human lung cancer H460 cells.

\section{Introduction}

Lung cancer accounts for $\sim 28 \%$ of cancer-associated mortalities (1), the occurrence of which is increasing worldwide. There are $\sim 1.2$ million novel cases of lung cancer and $\sim 1$ million mortalities from lung cancer each year (2). Lung cancer may be subdivided into small cell lung carcinoma and non-small cell lung carcinoma (NSCLC). The majority of lung cancer diagnoses are NSCLC $(3,4)$, which has a five-year survival rate of $33 \%$ (5). At present, the standard treatment for patients with resectable stage I to IIIA NSCLC is surgical excision; however, the prognosis remains poor (6). In addition, chemotherapy with or without surgery is not effective in the majority of cases; therefore, it is essential to identify novel compounds, including natural products, which may be employed for the treatment of lung cancer.

Cantharidin (CTD) is a component of mylabris (blister beetle), which has previously been used as a Traditional Chinese Medicine (7). Previous studies have reported that CTD induced cytotoxic effects in leukemia stem cells (8) as well as U937 (9), pancreatic cancer (10), hepatocellular carcinoma $(11,12)$, colon cancer $(13)$ and human lung cancer A549 (14) cells. In addition, CTD was found to inhibit the activity of protein phosphatase 2A (PP2A) (9) and heat shock factor 1 (HSF1) (15). Furthermore, it was shown that CTD induced cell death in human colorectal cancer cells, which was suggested to proceed through inhibiting the binding of heat shock protein 70 (HSP70), B cell lymphoma 2-associated athanogene domain 3 (BAG3) and HSF1 to promoters (15). 
Genetic mutations in oncogenes and tumor suppressor genes are present in cancer cells $(16,17)$. The development of cancer cells is well-known to be dependent on oncogenes for tumor initiation and progression; this concept has therefore been named oncogene addiction (18). Oncogenes are commonly used as targets for drug-screening programs (19); however, other signaling pathways have also been examined, such as the molecular chaperone pathway (20). The present study aimed to investigate the effect of CTD on the expression of key genes and functional pathways of human H460 lung cancer cells using complementary DNA microarray analysis. The results of the present study showed that CTD affected DNA damage, the cell cycle and the expression of apoptosis-associated genes in vitro. Differentially expressed genes were then used to generate interaction maps of signaling pathways. The epidermal growth factor and vascular endothelial growth factor receptor pathways, provided by the present study may be useful for the development of novel molecular targeted therapies against lung cancer (21).

\section{Materials and methods}

Chemicals and reagents. Cantharidin (CTD), propidium iodide and dimethyl sulfoxide (DMSO) were purchased from Sigma-Aldrich (St. Louis, MO, USA). Minimum essential medium (MEM), fetal bovine serum (FBS), L-glutamine and penicillin-streptomycin were purchased from Gibco-BRL (Carlsbad, CA, USA). CTD was dissolved in DMSO and stored at $20^{\circ} \mathrm{C}$.

Lung cancer cell culture. The NCI-H460 human lung cancer cell line was purchased from the Food Industry Research and Development Institute (Hsinchu, Taiwan). Cells were grown in MEM containing $10 \%$ (v/v) FBS as well as $100 \mathrm{U} / \mathrm{ml}$ penicillin and $100 \mu \mathrm{g} / \mathrm{ml}$ streptomycin in a $37^{\circ} \mathrm{C}$ humidified incubator with $5 \% \mathrm{CO}_{2}$. Cells were then subcultured once they reached $80-90 \%$ confluence, as previously described (22).

Complementary (c)DNA microarray assay. $\mathrm{H} 460$ cells were placed on 12 -well plates at a density of $5 \times 10^{5}$ cells/well in $2 \mathrm{ml} \mathrm{MEM}$ with $10 \%$ (v/v) FBS and $2 \mathrm{mM} \mathrm{L-glutamine,} \mathrm{as} \mathrm{well}$ as $100 \mathrm{U} / \mathrm{ml}$ penicillin and $100 \mu \mathrm{g} / \mathrm{ml}$ streptomycin for $24 \mathrm{~h}$. Subsequently, cells were treated with or without $10 \mu \mathrm{M}$ CTD for a further $24 \mathrm{~h}$. Cells $\left(3 \times 10^{6}\right)$ were then harvested and washed twice with phosphate-buffered saline (Gibco-BRL). Cells were lysed in TRIzol ${ }^{\circledR}$ (Invitrogen Life Technologies, Carlsbad, CA, USA) and total RNA was extracted using a Qiagen RNeasy Mini kit (Qiagen, Valencia, CA, USA). RNA concentrations were determined using a Qubit ${ }^{\mathrm{TM}}$ Fluorocytometer (Invitrogen Life Technologies).

Total RNA of CTD-treated and untreated H460 cells was used for cDNA synthesis. Samples were hybridized using an Affymetrix GeneChip Human Gene 1.0 ST array (Affymetrix, Santa Clara, CA, USA) according to the manufacturer's instructions. Sample fluorescence was quantified by Asia BioInnovations Corp. (Taipei, Taiwan), while data were analyzed using the Transcriptome Analysis Console ${ }^{\mathrm{TM}}$ 2.0 Version 2.0.0.9. (Affymetrix) with default robust multichip analysis parameters. A 2-fold change in gene expression was used as the threshold to indicate an effect on expression (7-10). An Oligo(dT) Maxime
RT PreMix kit (iNtRON Biotechnology, Gyeonggi-do, South Korea) was used to reverse transcribe RNA into cDNA. The Affymetrix GeneChip ${ }^{\circledR}$ Whole Transcript Sense Target (ST) Labeling (cat. no. 900673; 30 Rxn; Affymetrix, Santa Clara, CA, USA) assay is designed to generate amplified and biotinylated sense-strand DNA targets from the entire expressed genome without bias. This assay and associated reagents have been optimized specifically for use with the GeneChip ${ }^{\circledR}$ ST arrays, and the probes on the arrays have been selected to be distributed throughout the entire length of each transcript. The gene list complete with Affymetrix transcript identifiers, was uploaded from a spreadsheet onto Metacore 5.0 software (GeneGo pathways analysis; http://www.genego.com). GeneGo recognizes the Affymetrix identifiers and maps the gene to the MetaCore ${ }^{\mathrm{TM}}$ data analysis suite, generating maps to describe common pathways or molecular connections between genes in the list. Graphical representations of the molecular associations between the genes were generated using the GeneGo pathway analysis, based upon processes exhibiting a significant association $(\mathrm{P}<0.05)$.

Gene ontology analysis. For detection of significantly over-represented GO biological processes, the DAVID functional annotation clustering tool (http://david.abcc.ncifcrf.gov) was used (DAVID Bioinformatics Resources 6.7). Enrichment was determined at the DAVID calculated Benjamini value $<0.05$. The significance of the overexpression of individual genes was determined using Student's t-test.

Statistical analysis. Values are representative of three independent experiments. Differences between control and CTD-experimental groups are presented which $>2$-fold, where positive numbers represent upregulation and negative numbers represent downregulation.

\section{Results}

Upregulated and downregulated gene expression in H460 cells exposed to CTD. $\mathrm{H} 460$ cells were incubated in the presence or absence of $10 \mu \mathrm{M}$ CTD in a 12-well plate for $24 \mathrm{~h}$. Cells were then harvested and following the extraction of total RNA, RNA concentrations were determined and cDNA microarray analysis was performed in order to determine the expression of genes. The calculated upregulation and downregulation of gene expression, as determined by the microarray, are shown in Tables I and II, respectively. As shown in Table I, the results indicated that in CTD-treated $\mathrm{H} 460$ cells, 8 genes were upregulated $>4$-fold, 29 genes were upregulated $>3$-4-fold and 156 genes were upregulated $>2-3$-fold compared with expression levels in the untreated control cells. In addition, Table II indicated that one gene was downregulated $>4$ fold, 14 genes were downregulated $>3-4$ fold and 150 genes were downregulated $>2-3$ fold in H460 cells following exposure to CTD compared with those in the untreated control cells. The results presented in Table I demonstrated that genes associated with DNA damage, including DN1T3 and GADD45A were upregulated by 2.26-and 2.60-fold, respectively; in addition, the expression of genes associated with the cell cycle progression (check point proteins) were upregulated, including CCND2, CDKL3 and RASA4, which were upregulated 2.72-, 2.19- and 2.72-fold, respectively. Furthermore, the 
Table I. Upregulation of gene expression in catharidine-treated NCI-H460 cells.

\begin{tabular}{|c|c|c|c|c|}
\hline $\begin{array}{l}\text { Probe set } \\
\text { ID }\end{array}$ & $\begin{array}{c}\text { Fold } \\
\text { change }\end{array}$ & $\begin{array}{c}\text { Gene } \\
\text { symbol }\end{array}$ & Gene description & mRNA accession no. \\
\hline 8108370 & 16.50 & EGR1 & Early growth response 1 & NM_001964 \\
\hline 8012949 & 13.05 & CDRT1 & CMT1A duplicated region transcript 1 & NM_006382 \\
\hline 8012951 & 10.85 & CDRT1 & CMT1A duplicated region transcript 1 & NM_006382 \\
\hline 7916609 & 8.05 & JUN & Jun oncogene & NM_002228 \\
\hline 7977075 & 6.45 & SNORA28 & Small nucleolar RNA, H/ACA box 28 & NR_002964 \\
\hline 8041168 & 5.54 & SNORD53 & Small nucleolar RNA, C/D box 53 & NR_002741 \\
\hline 7982084 & 5.06 & SNORD115-11 & Small nucleolar RNA, C/D box 115-11 & NR_003303 \\
\hline 8097991 & 4.27 & TDO2 & Tryptophan 2,3-dioxygenase & NM_005651 \\
\hline 8114468 & 3.99 & SNORD63 & Small nucleolar RNA, C/D box 63 & NR_002913 \\
\hline 8158862 & 3.87 & SNORD62A & Small nucleolar RNA, C/D box $62 \mathrm{~A}$ & NR_002914 \\
\hline 8158864 & 3.87 & SNORD62A & Small nucleolar RNA, C/D box 62A & NR_002914 \\
\hline 8007420 & 3.85 & AOC3 & $\begin{array}{l}\text { Amine oxidase, copper-containing } 3 \\
\text { (vascular adhesion protein } 1 \text { ) }\end{array}$ & NM_003734 \\
\hline 7975779 & 3.81 & FOS & FBJ murine osteosarcoma viral oncogene homolog & NM_005252 \\
\hline 8001746 & 3.74 & SNORA46 & Small nucleolar RNA, H/ACA box 46 & NR_002978 \\
\hline 7914322 & 3.70 & SNORD103A & Small nucleolar RNA, C/D box 103A & NR_004054 \\
\hline 7914324 & 3.70 & SNORD103A & Small nucleolar RNA, C/D box 103A & NR_004054 \\
\hline 793342 & 3.69 & PTPN20A & Protein tyrosine phosphatase, non-receptor type 2 & NR_001042389 \\
\hline 7918467 & 3.65 & Clorf103 & Chromosome 1 open reading frame 103 & NM_018372 \\
\hline 8053797 & 3.60 & LOC400986 & $\begin{array}{l}\text { Protein immuno-reactive with anti-parathyroid } \\
\text { hormone polyclona }\end{array}$ & ENST00000456556 \\
\hline 8156848 & 3.59 & NR4A3 & Nuclear receptor subfamily 4 , group A, member 3 & NM_006981 \\
\hline 8005483 & 3.56 & FBXW10 & F-box and WD repeat domain-containing 10 & NM_031456 \\
\hline 8105077 & 3.54 & CARD6 & Caspase recruitment domain family, member 6 & NM_032587 \\
\hline 8139840 & 3.48 & ERV3 & Endogenous retroviral sequence 3 (includes zinc) & NM_001007253 \\
\hline 8030831 & 3.45 & ZNF175 & Zinc finger protein 175 & NM_007147 \\
\hline 7958200 & 3.45 & EID3 & EP300-interacting inhibitor of differentiation 3 & NM_001008394 \\
\hline 7936637 & 3.44 & SNORA19 & Small nucleolar RNA, H/ACA box 19 & NR_002917 \\
\hline 8107353 & 3.43 & ZRSR1 & $\begin{array}{l}\text { Zinc finger ( } \mathrm{CCCH} \text { type), RNA-binding motif and } \\
\text { serine/arginine rich } 1\end{array}$ & BC104811 \\
\hline 8173600 & 3.26 & NAP1L2 & Nucleosome assembly protein 1 -like 2 & NM_021963 \\
\hline 8126853 & 3.25 & C6orf138 & Chromosome 6 open reading frame 138 & NM_001013732 \\
\hline 8025301 & 3.20 & CD209 & CD209 molecule & NM_021155 \\
\hline 7923119 & 3.17 & ZBTB41 & Zinc finger and BTB domain-containing 41 & NM_194314 \\
\hline 7985555 & 3.11 & EFTUD1 & $\begin{array}{l}\text { Elongation factor Tu guanine triphosphate } \\
\text { binding domain-containing }\end{array}$ & NM_024580 \\
\hline 7952986 & 3.09 & HSN2 & Hereditary sensory neuropathy, type II & NM_213655 \\
\hline 8114572 & 3.08 & HBEGF & $\begin{array}{l}\text { Heparin-binding epidermal growth factor-like } \\
\text { growth factor }\end{array}$ & NM_001945 \\
\hline 8049540 & 3.05 & LRRFIP1 & Leucine-rich repeat (in FLII) interacting protein 1 & NM_001137550 \\
\hline 8047926 & 3.03 & MAP2 & Microtubule-associated protein 2 & NM_002374 \\
\hline 7954382 & 3.02 & PYROXD1 & $\begin{array}{l}\text { Pyridine nucleotide-disulphide oxidoreductase } \\
\text { domain } 1\end{array}$ & NM_024854 \\
\hline 7957260 & 2.99 & GLIPR1 & GLI pathogenesis-related 1 & NM_006851 \\
\hline 8054054 & 2.97 & ANKRD36B & Ankryin repeat domain $36 \mathrm{~B}$ & NM_025190 \\
\hline 7907572 & 2.96 & PAPPA2 & Pappalysin 2 & NM_020318 \\
\hline 8090688 & 2.93 & SNORA58 & Small nucleolar RNA, H/ACA box 58 & NR_002985 \\
\hline 8139935 & 2.89 & TYW1B & tRNA-yW synthesizing protein 1 homolog B & NM_001145440 \\
\hline 7982028 & 2.87 & SNORD115-11 & Small nucleolar RNA, C/D box 115-11 & NR_003303 \\
\hline 7982050 & 2.87 & SNORD115-11 & Small nucleolar RNA, C/D box 115-11 & NR_003303 \\
\hline 7982064 & 2.87 & SNORD115-11 & Small nucleolar RNA, C/D box 115-11 & NR_003303 \\
\hline
\end{tabular}


Table I. Continued.

\begin{tabular}{|c|c|c|c|c|}
\hline $\begin{array}{l}\text { Probe set } \\
\text { ID }\end{array}$ & $\begin{array}{l}\text { Fold } \\
\text { change }\end{array}$ & $\begin{array}{c}\text { Gene } \\
\text { symbol }\end{array}$ & Gene description & mRNA accession no. \\
\hline 7982078 & 2.87 & SNORD115-11 & Small nucleolar RNA, C/D box 115-11 & NR_003303 \\
\hline 7982092 & 2.87 & SNORD115-11 & Small nucleolar RNA, C/D box 115-11 & NR_003303 \\
\hline 7905339 & 2.86 & GABPB2 & GA binding protein transcription factor, $\beta$ subunit & NM_144618 \\
\hline 8140782 & 2.84 & ABCB1 & $\begin{array}{l}\text { ATP-binding cassette, sub-family B } \\
\text { (multidrug resistance protein/transporter associated } \\
\text { with antigen processing) }\end{array}$ & NM_000927 \\
\hline 8139482 & 2.83 & SNORA5A & Small nucleolar RNA, H/ACA box 5A & NR_002919 \\
\hline 8124756 & 2.83 & PPP1R10 & Protein phosphatase 1 , regulatory (inhibitor) subunit & NM_002714 \\
\hline 8124756 & 2.83 & PPP1R 10 & Protein phosphatase 1 , regulatory (inhibitor) subunit & NM_002714 \\
\hline 8178358 & 2.83 & PPP1R 10 & Protein phosphatase 1 , regulatory (inhibitor) subunit & NM_002714 \\
\hline 8179664 & 2.83 & PPP1R 10 & Protein phosphatase 1 , regulatory (inhibitor) subunit & NM_002714 \\
\hline 8112731 & 2.77 & F2RL2 & Coagulation factor II (thrombin) receptor-like 2 & NM_004101 \\
\hline 8043687 & 2.74 & ANKRD36 & Ankryin repeat domain 36 & NM_001164315 \\
\hline 7977273 & 2.74 & ADSSL1 & Adenylosuccinate synthase like 1 & NM_152328 \\
\hline 7953200 & 2.72 & CCND2 & Cyclin D2 & NM_001759 \\
\hline 8057954 & 2.72 & C2prf66 & Chromosome 2 open reading frame 66 & AY358249 \\
\hline 8049532 & 2.72 & LRRFIP1 & Leucine-rich repeat (in FLII) interacting protein 1 & NM_001137550 \\
\hline 8141843 & 2.72 & RASA4 & RAS p21 protein activator 4 & NM_006989 \\
\hline 8098752 & 2.72 & ABCA11P & $\begin{array}{l}\text { Adenosine triphosphate-binding cassette, } \\
\text { sub-family A, member } 11 \text {, pseudogene }\end{array}$ & NR_002451 \\
\hline 7982046 & 2.70 & SNORD115-20 & Small nucleolar RNA, C/D box 115-20 & NR_003312 \\
\hline 7982016 & 2.70 & SNORD115-12 & Small nucleolar RNA, C/D box 115-12 & NR_003304 \\
\hline 7982024 & 2.70 & SNORD115-12 & Small nucleolar RNA, C/D box 115-12 & NR_003304 \\
\hline 7982030 & 2.70 & SNORD115-12 & Small nucleolar RNA, C/D box 115-12 & NR_003304 \\
\hline 8054064 & 2.69 & ANKRD36B & Ankyrin repeat domain 36B & NM_025190 \\
\hline 7910047 & 2.68 & DNAH14 & Dynein, axonemal, heavy chain 14 & NM_001373 \\
\hline 8016239 & 2.68 & PLEKHM1 & $\begin{array}{l}\text { Pleckstrin homology domain-containing, family } \mathrm{M} \\
\text { (with RUN domain) member } 1\end{array}$ & NR_027774 \\
\hline 8060949 & 2.67 & ANKRD5 & Ankyrin repeat domain 5 & NM_022096 \\
\hline 8064375 & 2.62 & SRXN1 & Sulfiredoxin 1 homolog (S. Cerevisiae) & NM_080725 \\
\hline 8077612 & 2.61 & TTLL3 & Tubulin tyrosine ligase-like family, member 3 & NM_001025930 \\
\hline 8151559 & 2.60 & SLC10A5 & $\begin{array}{l}\text { Solute carrier family } 10 \text { (sodium/bile acid } \\
\text { cotransporter family), member } 5\end{array}$ & NM_001010893 \\
\hline 7902227 & 2.60 & GADD45A & Growth arrest and DNA-damage-inducible, $\alpha$ & NM_001924 \\
\hline 7982058 & 2.59 & SNORD115-26 & Small nucleolar RNA, C/D box 115-26 & NR_003343 \\
\hline 8118023 & 2.55 & GTF2H4 & General transcription factor II human, polypeptide 4 & NM_001517 \\
\hline 8006336 & 2.54 & LRRC37B & Leucine-rich repeat-containing 37B & NM_052888 \\
\hline 8108006 & 2.51 & LEAP2 & Liver-expressed antimicrobial peptide 2 & NM_052971 \\
\hline 7971388 & 2.50 & SLC25A30 & Solute carrier family 25, member 30 & NM_001010875 \\
\hline 7987163 & 2.48 & FMN1 & Formin 1 & ENST00000414268 \\
\hline 7938293 & 2.47 & SNORA45 & Small nucleolar RNA, H/ACA box 45 & NR_002977 \\
\hline 8113651 & 2.45 & ATG12 & ATG12 autophagy-related 12 homolog (S. Cerevisiae) & NR_033362 \\
\hline 8049542 & 2.45 & LRRFIP1 & Leucine-rich repeat (in FLII) interacting protein 1 & NM_001137550 \\
\hline 8097435 & 2.45 & C4orf33 & Chromosome 4 open reading frame 33 & NM_173487 \\
\hline 8168345 & 2.45 & ACRC & Acidic repeat-containing & NM_052957 \\
\hline 7980828 & 2.42 & CCDC88C & Coiled-coil domain-containing 88C & NM_001080414 \\
\hline 8045423 & 2.42 & SNORA40 & Small nucleolar RNA, H/ACA box 40 & NR_002973 \\
\hline 8112331 & 2.42 & ISCA1 & Iron-sulfur cluster assembly 1 homolog & NM_030940 \\
\hline 8043697 & 2.41 & ANKRD36B & Ankyrin repeat domain 36B & NM_025190 \\
\hline 8033667 & 2.40 & ZNF558 & Zinc finger protein 558 & NM_144693 \\
\hline 8142232 & 2.39 & LAMB4 & Laminin, $\beta 4$ & NM_007356 \\
\hline
\end{tabular}


Table I. Continued.

\begin{tabular}{|c|c|c|c|c|}
\hline $\begin{array}{l}\text { Probe set } \\
\text { ID }\end{array}$ & $\begin{array}{l}\text { Fold } \\
\text { change }\end{array}$ & $\begin{array}{l}\text { Gene } \\
\text { symbol }\end{array}$ & Gene description & mRNA accession no. \\
\hline 7960052 & 2.39 & SNORA49 & Small nuclear RNA, H/ACA box 49 & NR_002979 \\
\hline 8031837 & 2.39 & ZNF587 & Zinc finger protein 587 & AF294842 \\
\hline 8174715 & 2.38 & SNORA69 & Small nuclear RNA, H/ACA box 69 & NR_002584 \\
\hline 8001748 & 2.38 & SNORA50 & Small nuclear RNA, H/ACA box 50 & NR_002980 \\
\hline 8042503 & 2.38 & MXD1 & MAX dimerization protein 1 & NM_002357 \\
\hline 8072678 & 2.36 & HMOX1 & Heme oxygenase (decycling) 1 & NM_002133 \\
\hline 7997904 & 2.35 & ZNF778 & Zinc finger protein 778 & AK295122 \\
\hline 8053648 & 2.35 & KRCC1 & Lysine-rich coiled-coil 1 & NM_016618 \\
\hline 8035793 & 2.35 & ZNF737 & Zinc finger protein 737 & NM_001159293 \\
\hline 7977732 & 2.34 & SNORD8 & Small nuclear RNA, C/D box 8 & NR_002916 \\
\hline 8153457 & 2.31 & EEF1D & Eukaryotic translation elongation factor $1 \delta$ & AY358690 \\
\hline 8069574 & 2.31 & C21orf91 & Chromosome 21 open reading frame 91 & NM_001100420 \\
\hline 8112841 & 2.30 & HOMER 1 & Homer homolog 1 (Drosophila) & NM_004272 \\
\hline 8038919 & 2.29 & ZNF350 & Zinc finger protein 50 & NM_021632 \\
\hline 9175288 & 2.29 & MOSPD1 & Motile sperm domain-containing 1 & NM_019556 \\
\hline 8160912 & 2.28 & C9orf131 & Chromosome 9 open reading frame 131 & NM_203299 \\
\hline 7934334 & 2.28 & TTC18 & Tetratricopeptide repeat domain 18 & NM_145170 \\
\hline 8056572 & 2.27 & SPC25 & SPC25, NDC80 kinetochore complex component & NM_020675 \\
\hline 8161919 & 2.27 & TLE1 & Transducin-like enhancer of split 1 (Drosophila) & NM_005077 \\
\hline 7964460 & 2.26 & DDIT3 & DNA-damage-inducible transcript 3 & NM_004083 \\
\hline 8019857 & 2.26 & NDC80 & $\begin{array}{l}\text { NDC80 Homolog, kinetochore complex component } \\
\text { (S. cerevisiae) }\end{array}$ & NM_006101 \\
\hline 8045587 & 2.24 & ACVR2A & Activin A receptor, type IIA & NM_001616 \\
\hline 8002660 & 2.24 & TXNL4B & Thioredoxin-like 4B & NM_017853 \\
\hline 7911329 & 2.24 & 14-Sep & Septin 14 & NM_207366 \\
\hline 8080980 & 2.24 & FLJ10213 & Endogenous Borna-like N element- 1 & NM_018029 \\
\hline 8014115 & 2.22 & MYOID & Myosin ID & NM_015194 \\
\hline 7949916 & 2.20 & CHKA & Choline kinase $\alpha$ & NM_001277 \\
\hline 7938295 & 2.20 & RPL27A & Ribosomal protein L27a & NM_000990 \\
\hline 8168146 & 2.20 & KIF4A & Kinesin family member $4 \mathrm{~A}$ & NM_012310 \\
\hline 8114171 & 2.19 & CDKL3 & Cycline-dependent kinase-like 3 & NM_001113575 \\
\hline 8008700 & 2.19 & FLJ11710 & Hypothetical protein FLJ11710 & AK021772 \\
\hline 8108321 & 2.18 & FAM53C & Family with sequence similarity 53 , member $\mathrm{C}$ & NM_001135647 \\
\hline 8047161 & 2.18 & $\mathrm{OBFC} 2 \mathrm{~A}$ & $\begin{array}{l}\text { Oligonucleotide/oligosaccharide-binding } \\
\text { fold-containing } 2 \mathrm{a}\end{array}$ & NM_001031716 \\
\hline 8053576 & 2.17 & RNF103 & Ring finger protein 103 & NM_005667 \\
\hline 8006237 & 2.17 & LOC400590 & Hypothetical LOC400590 & ENST00000433145 \\
\hline 8136341 & 2.17 & BPGM & 2,3-bisphosphoglycerate mutase & NM_199186 \\
\hline 8146225 & 2.16 & C8orf40 & Chromosome 8 open reading frame 40 & NM_001135674 \\
\hline 8147057 & 2.16 & CHMP4C & Chromatin modifying protein $4 \mathrm{C}$ & NM_152284 \\
\hline 7921228 & 2.15 & ETV3 & E26 transforming-specific variant 3 & NM_001145312 \\
\hline 8065607 & 2.15 & PLAGL2 & Pleiomorphic adenoma gene-like 2 & NM_002657 \\
\hline 8096511 & 2.14 & BMPR1B & Bone morphogenetic protein receptor, type 1B & NM_001203 \\
\hline 7927389 & 2.14 & MAPK8 & Mitogen-activated protein kinase 8 & NM_002750 \\
\hline 8098958 & 2.14 & POLN & Polymerase (DNA directed) nu & NM_181808 \\
\hline 8038989 & 2.14 & ZNF600 & Zinc finger protein 600 & NM_198457 \\
\hline 7951654 & 2.14 & FDXACB1 & Ferredoxin-fold anticodon binding domain-containing 1 & NM_138378 \\
\hline 8036341 & 2.13 & ZNF461 & Zinc finger protein 461 & NM_153257 \\
\hline 7981998 & 2.13 & SNORD116-25 & Small nucleolar RNA, C/D box 116-25 & NM_003339 \\
\hline 8041179 & 2.13 & CLIP4 & $\begin{array}{l}\text { Cytoskeleton-associated protein-glycine-rich } \\
\text { domain-containing linker protein family member } 4\end{array}$ & NM_024692 \\
\hline
\end{tabular}


Table I. Continued.

\begin{tabular}{|c|c|c|c|c|}
\hline $\begin{array}{l}\text { Probe set } \\
\text { ID }\end{array}$ & $\begin{array}{l}\text { Fold } \\
\text { change }\end{array}$ & $\begin{array}{c}\text { Gene } \\
\text { symbol }\end{array}$ & Gene description & mRNA accession no. \\
\hline 7969096 & 2.13 & CDADC1 & $\begin{array}{l}\text { Cytidine and deoxycytidine monophosphate } \\
\text { deaminase domain-containing } 1\end{array}$ & NM_030911 \\
\hline 7969243 & 2.13 & CKAP2 & Cytoskeleton-associated protein 2 & NM_018204 \\
\hline 7986350 & 2.12 & ARRDC4 & Arrestin domain-containing 4 & NM_183376 \\
\hline 8063382 & 2.12 & SNAI1 & Snail homolog 1 (Drosophila) & NM_005985 \\
\hline 8053801 & 2.12 & ANKRD36 & Ankyrin repeat domain 36 & NM_001164315 \\
\hline 7999588 & 2.12 & PLA2G10 & Phospholipase A2, group X & NM_003561 \\
\hline 8008795 & 2.11 & C17orf71 & Chromosome 17 open reading frame 71 & NM_018149 \\
\hline 8029340 & 2.11 & ZNF155 & Zinc finger protein 155 & NM_003445 \\
\hline 8166104 & 2.11 & OFD1 & Oral-facial-digital syndrome 1 & NM_003611 \\
\hline 8123825 & 2.11 & SLC35B3 & Solute carrier family 35 member B3 & NM_015948 \\
\hline 7901052 & 2.11 & SNORD38B & Small nucleolar RNA, C/D box 38B & NM_001457 \\
\hline 8084880 & 2.10 & HES 1 & Hairy and enhancer of split 1 & NM_005524 \\
\hline 7925672 & 2.10 & ZNF670 & Zinc finger protein 670 & NM_033213 \\
\hline 7982294 & 2.10 & OTUD7A & OTU domain-containing 7A & NM_130901 \\
\hline 7962112 & 2.09 & CAPRIN2 & Caprin family member 2 & NM_001002259 \\
\hline 7973948 & 2.09 & BRMSIL & Breast cancer metastasis-suppressor 1-like & NM_032352 \\
\hline 8117685 & 2.09 & ZKSCAN3 & Zinc finger with KRAB and SCAN domains 3 & NM_024493 \\
\hline 8010082 & 2.08 & SNORD1A & Small nucleolar RNA, C/D box 1A & NR_004395 \\
\hline 8041982 & 2.08 & ACYP2 & Acylphosphatase 2 , muscle type & NM_138448 \\
\hline 8137693 & 2.08 & COX19 & Cytochrome c oxidase assembly homolog 19 & NM_001031617 \\
\hline 7917779 & 2.08 & GCLM & Glutamate-cysteine ligase, modifier subunit & NM_002061 \\
\hline 7938364 & 2.08 & WEE1 & WEE1 homolog 1 (S. Pombe) & BX641032 \\
\hline 8007414 & 2.08 & $\mathrm{AOC} 2$ & Amine oxidase, copper-containing 2 (retina-specific) & NM_009590 \\
\hline 8139656 & 2.08 & GRB 10 & Growth factor receptor-bound protein 10 & NM_001001555 \\
\hline 8059852 & 2.08 & $\begin{array}{l}\text { MSL3L2/ } \\
\text { MSL3-like } 2\end{array}$ & Male-specific lethal 3-like 2 (Drosophila) & NM_001166217 \\
\hline 8109484 & 2.07 & KIF4B & Kinesin family member 4B & NM_001099293 \\
\hline 8022559 & 2.07 & ANKRD29 & Ankyrin repeat domain 29 & NM_173505 \\
\hline 7910030 & 2.07 & DNAH14 & Dynein, axonemal, heavy chain 14 & NM_00145154 \\
\hline 8052143 & 2.07 & GPR75 & G protein-coupled receptor 75 & NM_006794 \\
\hline 7931643 & 2.07 & CYP2E1 & Cytochrome P450, family 2, subfamily E, polypeptide 1 & NM_000773 \\
\hline 8102789 & 2.06 & TERF1 & Telomeric repeat binding factor (NIMA-interacting) 1 & NM_003218 \\
\hline 7953603 & 2.06 & $\mathrm{C} 1 \mathrm{~S}$ & Complement component $1, \mathrm{~s}$ subcomponent & NM_201442 \\
\hline 8104930 & 2.05 & SLC1A3 & $\begin{array}{l}\text { Solute carrier family } 1 \text { (glial high affinity glutamate } \\
\text { transporter), member } 3\end{array}$ & NM_004172 \\
\hline 7953211 & 2.05 & C12orf5 & Chromosome 12 open reading frame 5 & NM_020375 \\
\hline 8114326 & 2.04 & FAM13B & Family with sequence similarity 13, member B & NM_0166603 \\
\hline 7936826 & 2.04 & IKZF5 & IKAROS family zinc finger (Pegasus) & NM_022466 \\
\hline 8013567 & 2.04 & C17orf108 & Chromosome 17 open reading frame 108 & NM_001076680 \\
\hline 7975066 & 2.04 & AKAP5 & A-kinase anchor protein 5 & NM_004857 \\
\hline 8142524 & 2.04 & TSPAN12 & Tetraspanin 12 & NM_012338 \\
\hline 7952673 & 2.04 & FLJ45950 & FLJ45950 protein & AK127847 \\
\hline 8081128 & 2.04 & NSUN3 & $\begin{array}{l}\text { Nucleolar protein } 2 \text { homolog/Sun domain family, } \\
\text { member } 3\end{array}$ & NM_022072 \\
\hline 7922846 & 2.04 & FAM129A & Family with sequence similarity 129, member A & NM_052966 \\
\hline 8013305 & 2.04 & ZNF286B & Zinc finger protein $286 \mathrm{~B}$ & NM_001145045 \\
\hline 8153935 & 2.03 & ZNF252 & Zinc finger protein 252 & NM_023392 \\
\hline 8162490 & 2.03 & HIATL1 & Hippocampus abundant transcript-like 1 & NM_032558 \\
\hline 8128698 & 2.02 & SESN1 & Sestrin 1 & NM_014454 \\
\hline 8010778 & 2.02 & CSNK1D & Casein kinase $1, \delta$ & NM_001893 \\
\hline
\end{tabular}


Table I. Continued.

\begin{tabular}{|c|c|c|c|c|}
\hline $\begin{array}{l}\text { Probe set } \\
\text { ID }\end{array}$ & $\begin{array}{l}\text { Fold } \\
\text { change }\end{array}$ & $\begin{array}{l}\text { Gene } \\
\text { symbol }\end{array}$ & Gene description & mRNA accession no. \\
\hline 8141311 & 2.02 & FAM200A & $\begin{array}{l}\text { Family with sequence similarity } 200 \text {, } \\
\text { member A }\end{array}$ & NM_145111 \\
\hline 7944867 & 2.02 & SIAE & Sialic acid acetylesterase & NM_170601 \\
\hline 7961829 & 2.02 & BCAT1 & $\begin{array}{l}\text { Branched-chain amino-acid transaminase } 1 \text {, } \\
\text { cytosolic }\end{array}$ & NM_005504 \\
\hline 7994161 & 2.02 & RBBP6 & Etinoblastoma binding protein 6 & NM_006910 \\
\hline 7981273 & 2.02 & CCDC85C & Coiled-coil domain-containing $85 \mathrm{C}$ & NM_001144995 \\
\hline 8110649 & 2.02 & TRIM41 & Tripartite motif-containing 41 & NM_033549 \\
\hline 8101839 & 2.01 & EIF4E & Eukaryotic translation initiation factor $4 \mathrm{E}$ & NM_001968 \\
\hline 8103226 & 2.01 & TMEM154 & Transmembrane protein 154 & NM_152680 \\
\hline
\end{tabular}

Table II. Downregulation of gene expressions in catharidine-treated NCI-H460 cells.

\begin{tabular}{|c|c|c|c|c|}
\hline $\begin{array}{l}\text { Probe set } \\
\text { ID }\end{array}$ & $\begin{array}{l}\text { Fold } \\
\text { change }\end{array}$ & $\begin{array}{l}\text { Gene } \\
\text { symbol }\end{array}$ & Gene description & mRNA accession no. \\
\hline 8175016 & -3.08 & APLN & Apelin & NM_017413 \\
\hline 8124413 & -3.06 & HIST1H4D & Histone cluster $1, \mathrm{H} 4 \mathrm{~d}$ & NM_003539 \\
\hline 8105302 & -3.05 & FST & Follistatin & NM_006350 \\
\hline 7953665 & -3.04 & DPPA3 & Developmental pluripotency-associated 3 & NM_199286 \\
\hline 8117426 & -2.99 & HIST1H2BH & Histone cluster $1, \mathrm{H} 2 \mathrm{bh}$ & NM_003524 \\
\hline 8117898 & -2.97 & HIST1H4J & Histone cluster $1, \mathrm{H} 4 \mathrm{j}$ & NM_021968 \\
\hline 8117337 & -2.95 & HIST1H1E & Histone cluster $1, \mathrm{H} 1 \mathrm{e}$ & NM_005321 \\
\hline 7911241 & -2.93 & OR2L8 & Olfactory receptor, family 2 , subfamily L, member 8 & NM_001001963 \\
\hline 8048749 & -2.88 & KCNE4 & $\begin{array}{l}\text { Potassium voltage-gated channel, IsK-related } \\
\text { family, member } 4\end{array}$ & NM_080671 \\
\hline 8124437 & -2.87 & HIST1H3F & Histone cluster $1, \mathrm{H} 3 \mathrm{f}$ & NM_021018 \\
\hline 8117395 & -2.83 & HIST1H2BF & Histone cluster $1, \mathrm{H} 2 \mathrm{bf}$ & NM_003522 \\
\hline 8015798 & -2.79 & LOC100130581 & Hypothetical LOC100130581 & NR_027413 \\
\hline 7919642 & -2.78 & HIST2H2AB & Histone cluster $2, \mathrm{H} 2 \mathrm{ab}$ & NM_175065 \\
\hline 8059470 & -2.76 & IRS1 & Insulin receptor substrate 1 & NM_005544 \\
\hline 8077270 & -2.75 & CHL1 & $\begin{array}{l}\text { Cell adhesion molecule with homology to } \\
\text { L1 cell adhesion molecule }\end{array}$ & NM_006614 \\
\hline 7915592 & -2.74 & RNU5D & RNA, U5D small nuclear & NR_002755 \\
\hline 7906767 & -2.74 & FCGR2C & $\begin{array}{l}\text { Fc fragment of immunoglobulin } \mathrm{G} \text {, low affinity IIc, } \\
\text { receptor for (CD32) (gene/pseudogene) }\end{array}$ & NM_201563 \\
\hline 8117594 & -2.74 & HIST1H2BM & Histone cluster $1, \mathrm{H} 2 \mathrm{bm}$ & NM_003521 \\
\hline 8117589 & -2.72 & HIST1H3H & Histone cluster $1, \mathrm{H} 3 \mathrm{~h}$ & NM_003536 \\
\hline 7981728 & -2.71 & LOC100293211 & Similar to hCG2042717 & ENST00000390601 \\
\hline 8124397 & -2.71 & HIST1H1C & Histone cluster $1, \mathrm{H} 1 \mathrm{c}$ & NM_005319 \\
\hline 8135734 & -2.71 & C7orf58 & Chromosome 7 open reading frame 58 & NM_024913 \\
\hline 8138988 & -2.70 & DPY19L2P1 & Dpy-19-like 2 pseudogene 1 (C.elegans) & NR_002833 \\
\hline 8117583 & -2.65 & HIST1H2AI & Histone cluster 1, H2ai & NM_003509 \\
\hline 8153258 & -2.65 & SLC45A4 & Solute carrier family 45, member 4 & ВС033223 \\
\hline 7960865 & -2.61 & SLC2A3 & $\begin{array}{l}\text { Solute carrier family } 2 \text { (facilitated glucose } \\
\text { transporter), member } 3\end{array}$ & NM_006931 \\
\hline 8116921 & -2.59 & EDN1 & Endothelin 1 & NM_001955 \\
\hline 8101757 & -2.58 & GPRIN3 & $\begin{array}{l}\text { G protein-regulated inducer of neurite } \\
\text { outgrowth family member } 3\end{array}$ & NM_198281 \\
\hline 7971723 & -2.58 & FLJ37307 & Hypothetical LOC283521 & NR_027047 \\
\hline
\end{tabular}


Table II. Continued.

\begin{tabular}{|c|c|c|c|c|}
\hline $\begin{array}{l}\text { Probe set } \\
\text { ID }\end{array}$ & $\begin{array}{l}\text { Fold } \\
\text { change }\end{array}$ & $\begin{array}{c}\text { Gene } \\
\text { symbol }\end{array}$ & Gene description & mRNA accession no. \\
\hline 8117580 & -2.56 & HIST1H2AI & Histone cluster $1, \mathrm{H} 2 \mathrm{ai}$ & NM_003509 \\
\hline 8167573 & -2.56 & GAGE1 & G antigen 1 & NM_001468 \\
\hline 8165295 & -2.56 & LCN8 & Lipocalin 8 & ENST00000371686 \\
\hline 7927876 & -2.53 & TET1 & Ten-eleven translocation oncogene 1 & NM_030625 \\
\hline 7963054 & -2.52 & TUBA1A & Tubulin, $\alpha 1 \mathrm{a}$ & NM_006009 \\
\hline 7957386 & -2.51 & ACSS3 & Acyl-CoA synthetase short-chain family member 3 & NM_024560 \\
\hline 7915919 & -2.49 & TAL1 & T cell acute lymphocytic leukemia 1 & NM_003189 \\
\hline 8174985 & -2.48 & SMARCA1 & $\begin{array}{l}\text { Switch/sucrose non-fermentable-related, } \\
\text { matrix-associated, actin-dependent regulator } \\
\text { of chromatin, subfamily a, member } 1\end{array}$ & NM_003069 \\
\hline 8105495 & -2.47 & PART1 & $\begin{array}{l}\text { Prostate androgen-regulated transcript } 1 \\
\text { (non-protein coding) }\end{array}$ & NR_028508 \\
\hline 8146967 & -2.46 & CRISPLD1 & $\begin{array}{l}\text { Cysteine-rich secretory protein LCCL } \\
\text { domain-containing } 1\end{array}$ & NM_031461 \\
\hline 8144786 & -2.46 & SLC7A2 & $\begin{array}{l}\text { Solute carrier family } 7 \text { (cationic amino acid } \\
\text { transporter, y+ system), member } 2\end{array}$ & NM_003046 \\
\hline 8029280 & -2.45 & CD177 & CD177 molecule & NM_020406 \\
\hline 7984524 & -2.45 & PAQR5 & Progestin and adipoQ receptor family member $\mathrm{V}$ & NM_001104554 \\
\hline 7973182 & -2.44 & LOC554207 & Hypothetical LOC554207 & ENST00000320322 \\
\hline 8145795 & -2.44 & LOC100293539 & Similar to ribosomal protein 10 & XM_002346094 \\
\hline 8095697 & -2.44 & CXCL1 & $\begin{array}{l}\text { Chemokine (C-X-C motif) ligand } 1 \text { (melanoma } \\
\text { growth stimulating activity, } \alpha \text { ) }\end{array}$ & NM_001511 \\
\hline 8124406 & -2.42 & HIST1H2BC & Histone cluster $1, \mathrm{H} 2 \mathrm{bc}$ & NM_003526 \\
\hline 7978260 & -2.42 & DHRS1 & Dehydrogenase/reductase family member 1 & NM_001136050 \\
\hline 7920271 & -2.42 & S100A4 & S100 calcium binding protein A4 & NM_019544 \\
\hline 8166469 & -2.42 & SAT1 & Spermidine/spermine N1-acetyltransferase 1 & NR_027783 \\
\hline 8124527 & -2.40 & HIST1H1B & Histone cluster $1, \mathrm{H} 1 \mathrm{~b}$ & NM_005322 \\
\hline 8008321 & -2.40 & ACSF2 & Acyl-CoA synthetase family member 2 & NM_025149 \\
\hline 8124385 & -2.39 & HIST1H4B & Histone cluster $1, \mathrm{H} 4 \mathrm{~b}$ & NM_003544 \\
\hline 800731 & -2.38 & TUBG2 & Tubulin, $\gamma 2$ & NM_016437 \\
\hline 8122365 & -2.36 & GPR126 & G protein-coupled receptor 126 & NM_020455 \\
\hline 8015273 & -2.34 & KRT31 & Keratin 31 & NM_002277 \\
\hline 7904465 & -2.34 & HIST2H2BA & Histone cluster $2, \mathrm{H} 2 \mathrm{ba}$ & NR_027337 \\
\hline 8124416 & -2.33 & HIST1H3D & Histone cluster $1, \mathrm{H} 3 \mathrm{~d}$ & NM_003530 \\
\hline 8074458 & -2.33 & C22orf39 & Chromosome 22 open reading frame 39 & NM_173793 \\
\hline 8046048 & -2.33 & CSRNP3 & Cysteine-serine-rich nuclear protein 3 & NM_001172173 \\
\hline 8007493 & -2.32 & ARL4D & Adenosine diphosphate-ribosylation factor-like 4D & NM_001661 \\
\hline 8157804 & -2.31 & OLFML2A & Olfactomedin-like 2A & NM_182487 \\
\hline 7948836 & -2.31 & TMEM223 & Transmembrane protein 223 & NM_001080501 \\
\hline 8033458 & -2.31 & LYPLA2 & Lysophospholipase II & NM_007260 \\
\hline 7919619 & -2.30 & HIST2H2AA3 & histone cluster $2, \mathrm{H} 2 \mathrm{aa} 3$ & NM_003516 \\
\hline 7905079 & -2.30 & HIST2H2AA3 & Histone cluster $2, \mathrm{H} 2 \mathrm{aa} 3$ & NM_003516 \\
\hline 7927631 & -2.29 & DKK1 & Dickkopf homolog 1 (Xenopus laevis) & NM_012242 \\
\hline 7975598 & -2.28 & ACOT1 & Acyl-CoA thioesterase 1 & NM_001037161 \\
\hline 8071801 & -2.27 & GSTTP1 & Glutathione S-transferase $\theta$ pseudogene 1 & NR_003081 \\
\hline 7928429 & -2.27 & PLAU & Plasminogen activator, urokinase & NM_002658 \\
\hline 8068898 & -2.27 & HIST1H2BK & Histone cluster $1, \mathrm{H} 2 \mathrm{bk}$ & NM_080593 \\
\hline 8041467 & -2.26 & VIT & Vitrin & NM_053276 \\
\hline 8077160 & -2.26 & ARSA & Arylsulfatase A & NM_000487 \\
\hline 7991754 & -2.25 & HBZ & Hemoglobin, $\zeta$ & NM_005332 \\
\hline 8049534 & -2.24 & LRRFIP1 & Leucine-rich repeat (in FLII) interacting protein 1 & NM_001137550 \\
\hline
\end{tabular}


Table II. Continued.

\begin{tabular}{|c|c|c|c|c|}
\hline $\begin{array}{l}\text { Probe Set } \\
\text { ID }\end{array}$ & $\begin{array}{l}\text { Fold } \\
\text { change }\end{array}$ & $\begin{array}{l}\text { Gene } \\
\text { symbol }\end{array}$ & Gene description & mRNA accession no. \\
\hline 7909789 & -2.23 & TGFB2 & Transforming growth factor $\beta 2$ & NM_001135599 \\
\hline 7919612 & -2.23 & HIST2H3D & Histone cluster $2, \mathrm{H} 3 \mathrm{~d}$ & NM_001123375 \\
\hline 8100578 & -2.22 & EPHA5 & Ephrin receptor A5 & NM_004439 \\
\hline 8169541 & -2.22 & DOCK11 & Dedicator of cytokinesis 11 & NM_144658 \\
\hline 8124430 & -2.21 & HIST1H1D & Histone cluster $1, \mathrm{H} 1 \mathrm{~d}$ & NM_005320 \\
\hline 8124524 & -2.21 & HIST1H2AK & Histone cluster $1, \mathrm{H} 2 \mathrm{ak}$ & NM_003510 \\
\hline 8124524 & -2.21 & HIST1H2AK & Histone cluster $1, \mathrm{H} 2 \mathrm{ak}$ & NM_003510 \\
\hline 7906775 & -2.20 & HSPA7 & Heat shock 70kDa protein 7 (HSP70B) & NR_024151 \\
\hline 7953291 & -2.20 & CD9 & CD9 molecule & NM_001769 \\
\hline 8033319 & -2.19 & SH2D3A & Src Homology 2 domain-containing 3A & NM_005490 \\
\hline 7905088 & -2.19 & HIST2H2AC & Histone cluster $2, \mathrm{H} 2 \mathrm{ac}$ & NM_003517 \\
\hline 7975602 & -2.19 & ACOT2 & Acyl-CoA thioesterase 2 & NM_006821 \\
\hline 7982854 & -2.19 & DLL4 & §-like 4 (Drosophila) & NM_019074 \\
\hline 8019778 & -2.19 & PCYT2 & Phosphate cytidylyltransferase 2 , ethanolamine & NM_002861 \\
\hline 8046048 & -2.19 & HIST1H4C & Histone cluster $1, \mathrm{H} 4 \mathrm{c}$ & NM_003542 \\
\hline 8007493 & -2.18 & VWA5A & Von Willebrand factor A domain-containing 5A & NM_001130142 \\
\hline 8157804 & -2.18 & PLG & Plasminogen & NM_000301 \\
\hline 7948836 & -2.18 & CD24 & CD24 molecule & NM_013230 \\
\hline 8033458 & -2.17 & FSTL4 & Follistatin-like 4 & NM_015082 \\
\hline 7919619 & -2.16 & CA2 & Carbonic anhydrase II & NM_000067 \\
\hline 7905079 & -2.16 & CDH19 & Cadherin 19 , type 2 & NM_021153 \\
\hline 7927631 & -2.16 & CDC42EP3 & $\begin{array}{l}\text { Cell division cycle } 42 \text { effector protein (Rho } \\
\text { guanosine triphosphatase binding) } 3\end{array}$ & NM_006449 \\
\hline 7975598 & -2.16 & ACCN2 & Amiloride-sensitive cation channel 2, neuronal & NM_020039 \\
\hline 8071801 & -2.15 & HIST2H3D & Histone cluster $2, \mathrm{H} 3 \mathrm{~d}$ & NM_001123375 \\
\hline 7928429 & -2.15 & RFX2 & $\begin{array}{l}\text { Regulatory factor X, } 2 \text { (influences human } \\
\text { leukocyte antigen class II expression) }\end{array}$ & NM_000635 \\
\hline 8068898 & -2.15 & NES & Nestin & NM_006617 \\
\hline 8041467 & -2.15 & LOC25845 & Hypothetical LOC25845 & NR_024158 \\
\hline 8077160 & -2.15 & THSD7A & Thrombospondin, type I, domain-containing 7A & NM_015204 \\
\hline 7991754 & -2.14 & LOC147727 & Hypothetical LOC147727 & NR_024333 \\
\hline 8049534 & -2.14 & CALML6 & Calmodulin-like 6 & NM_138705 \\
\hline 7909789 & -2.14 & DEFB109P1B & Defensin, $\beta$ 109, pseudogene 1B & NR_003668 \\
\hline 7919612 & -2.13 & EPOR & Erythropoietin receptor & NM_000121 \\
\hline 8100578 & -2.13 & EEF2K & Eukaryotic elongation factor-2 kinase & NM_013302 \\
\hline 8169541 & -2.13 & EMP3 & Epithelial membrane protein 3 & NM_001425 \\
\hline 8124430 & -2.13 & TMEM84 & Transmembrane protein 84 & NR_026949 \\
\hline 8124524 & -2.13 & CXXC5 & CXXC finger 5 & NM_016463 \\
\hline 7906775 & -2.12 & PCYT2 & Phosphate cytidylyltransferase 2 , ethanolamine & NM_002861 \\
\hline 7953291 & -2.12 & LYPD1 & $\begin{array}{l}\text { Ly6/plasminogen activator, urokinase } 1 \\
\text { receptor domain-containing }\end{array}$ & NM_144586 \\
\hline 8033319 & -2.12 & PHLDB2 & $\begin{array}{l}\text { Pleckstrin homology-like domain, family B, } \\
\text { member } 2\end{array}$ & NM_001134439 \\
\hline 7905088 & -2.11 & LRFN2 & $\begin{array}{l}\text { Leucine-rich repeat and fibronectin type III } \\
\text { domain-containing } 2\end{array}$ & NM_020737 \\
\hline 7975602 & -2.11 & C9orf23 & Chromosome 9 open reading frame 23 & NM_148179 \\
\hline 7982854 & -2.11 & FLJ13744 & Hypothetical FLJ13744 & ВC070061 \\
\hline 8018445 & -2.11 & UNK & Unkempt homolog (Drosophila) & NM_001080419 \\
\hline 8038407 & -2.10 & RRAS & Related RAS viral (r-ras) oncogene homolog & NM_006270 \\
\hline 7987230 & -2.10 & LPCAT4 & Lysophosphatidylcholine acyltransferase 4 & NM_153613 \\
\hline 8031514 & -2.10 & LOC100133142 & Hypothetical LOC100133142 & XM_001718400 \\
\hline
\end{tabular}


Table II. Continued.

\begin{tabular}{|c|c|c|c|c|}
\hline $\begin{array}{l}\text { Probe set } \\
\text { ID }\end{array}$ & $\begin{array}{l}\text { Fold } \\
\text { Change }\end{array}$ & $\begin{array}{l}\text { Gene } \\
\text { Symbol }\end{array}$ & Gene description & mRNA accession no. \\
\hline 8130374 & -2.10 & FBXO5 & F-box protein 5 & NM_012177 \\
\hline 7908409 & -2.09 & RGS2 & Regulator of G-protein signaling 2 & NM_002923 \\
\hline 8111255 & -2.09 & CDH10 & Cadherin 10, type 2 (T2-cadherin) & NM_006727 \\
\hline 7965335 & -2.09 & DUSP6 & Dual specificity phosphatase 6 & NM_001946 \\
\hline 8065537 & -2.09 & LOC100134868 & Hypothetical LOC100134868 & NR_004846 \\
\hline 8138466 & -2.08 & MACC1 & Metastasis associated in colon cancer 1 & NM_182762 \\
\hline 7902687 & -2.08 & CYR61 & Cysteine-rich, angiogenic inducer, 61 & NM_001554 \\
\hline 8036136 & -2.08 & TMEM149 & Transmembrane protein 149 & NM_024660 \\
\hline 8098916 & -2.08 & TMEM129 & Transmembrane protein 129 & NM_001127266 \\
\hline 7955663 & -2.07 & TENC1 & $\begin{array}{l}\text { Tensin-like } \mathrm{C} 1 \text { domain-containing phosphatase } \\
\text { (tensin 2) }\end{array}$ & NM_170754 \\
\hline 7939897 & -2.07 & FOLH1 & $\begin{array}{l}\text { Folate hydrolase (prostate-specific membrane } \\
\text { antigen) } 1\end{array}$ & NM_004476 \\
\hline 7920191 & -2.07 & LCE3A & Late cornified envelope $3 \mathrm{~A}$ & NM_178431 \\
\hline 7951437 & -2.06 & GUCY1A2 & Guanylate cyclase 1 , soluble, $\alpha 2$ & NM_000855 \\
\hline 8022653 & -2.06 & LOC728606 & Hypothetical LOC728606 & NR_024259 \\
\hline 7929816 & -2.06 & SCD & Stearoyl-CoA desaturase ( $\delta$ - 9 -desaturase) & NM_005063 \\
\hline 7940565 & -2.06 & FADS2 & Fatty acid desaturase 2 & NM_004265 \\
\hline 7951157 & -2.06 & CCDC82 & Coiled-coil domain-containing 82 & AK313893 \\
\hline 7936100 & -2.06 & CALHM2 & Calcium homeostasis modulator 2 & NM_015916 \\
\hline 7954090 & -2.06 & EMP1 & Epithelial membrane protein 1 & NM_001423 \\
\hline 8005951 & -2.05 & SNORD42B & Small nucleolar RNA, C/D box 42B & NR_000013 \\
\hline 8148917 & -2.05 & MFSD3 & Major facilitator superfamily domain-containing 3 & NM_138431 \\
\hline 7937990 & -2.04 & HBG1 & Hemoglobin, $\gamma \mathrm{A}$ & NM_000559 \\
\hline 7937993 & -2.04 & HBG2 & Hemoglobin, $\gamma \mathrm{G}$ & NM_000184 \\
\hline 8033233 & -2.04 & TUBB4 & Tubulin, $\beta 4$ & NM_006087 \\
\hline 8048350 & -2.04 & PLCD4 & Phospholipase C, $\delta 4$ & NM_032726 \\
\hline 8037408 & -2.04 & KCNN4 & $\begin{array}{l}\text { Potassium intermediate/small conductance } \\
\text { calcium-activated channel, subfamily } \mathrm{N} \text {, member } 4\end{array}$ & NM_002250 \\
\hline 7964119 & -2.04 & STAT2 & Signal transducer and activator of transcription 2 & NM_005419 \\
\hline 8016841 & -2.03 & TMEM100 & Transmembrane protein 100 & NM_001099640 \\
\hline 7958948 & -2.03 & DDX54 & DEAD box polypeptide 54 & NM_0011111322 \\
\hline 8151512 & -2.02 & PAG1 & $\begin{array}{l}\text { Phosphoprotein associated with } \\
\text { glycosphingolipid microdomains } 1\end{array}$ & NM_018440 \\
\hline 8005549 & -2.02 & GRAPL & $\begin{array}{l}\text { Growth factor receptor-bound protein 2-related } \\
\text { adaptor protein-like }\end{array}$ & NM_001129778 \\
\hline 8033159 & -2.02 & PSPN & Persephin & NM_004158 \\
\hline 7986639 & -2.02 & VSIG6 & V-set and immunoglobulin domain-containing 6 & ENST00000338567 \\
\hline 7938741 & -2.01 & MRGPRX3 & $\begin{array}{l}\text { MAS-related G protein coupled receptor, } \\
\text { member X3 }\end{array}$ & NM_054031 \\
\hline 8047174 & -2.01 & SLC39A10 & $\begin{array}{l}\text { Solute carrier family } 39 \text { (zinc transporter), } \\
\text { member } 10\end{array}$ & NM_001127257 \\
\hline
\end{tabular}

Acyl-CoA, acyl coenzyme A; DEAD, (Asp-Glu-Ala-Asp).

expression of apoptosis-associated genes was upregulated, such as CARD6, which was upregulated 3.54-fold (Table I). By contrast, the results presented in Table II demonstrated that genes associated with DNA damage, cell cycle progression and apoptosis were also downregulated, including DdiT4, CDC42EP3 and STAT2, respectively. These genes were found to be downregulated 3.14-, 2.16 and 2.04-fold, respectively (Table II). Overall, cDNA microarray analysis of H460 cells following treatment with CTD demonstrated that CTD induced the differential expression of numerous genes associated with DNA damage, cell cycle progression and apoptosis. 


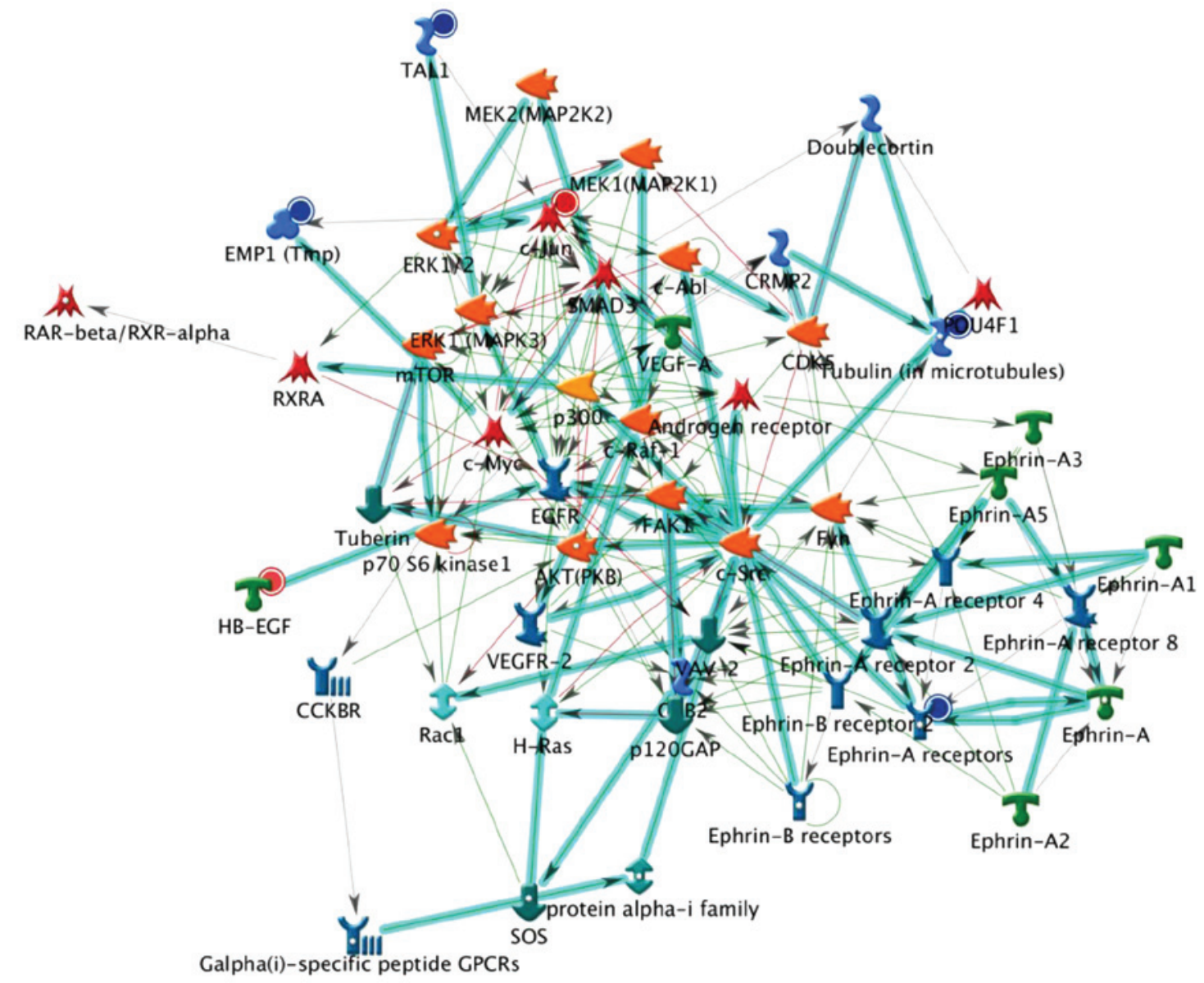

Figure 1. Top scored (by the number of pathways) AN network, as determined using GeneGo_cat_FC2 analysis. Thick cyan lines indicate the fragments of canonical pathways. Upregulated genes are marked with red circles and downregulated genes are indicated with blue circles. FC, Fold Change 2.0; AN, Analyze Networks algorithm.

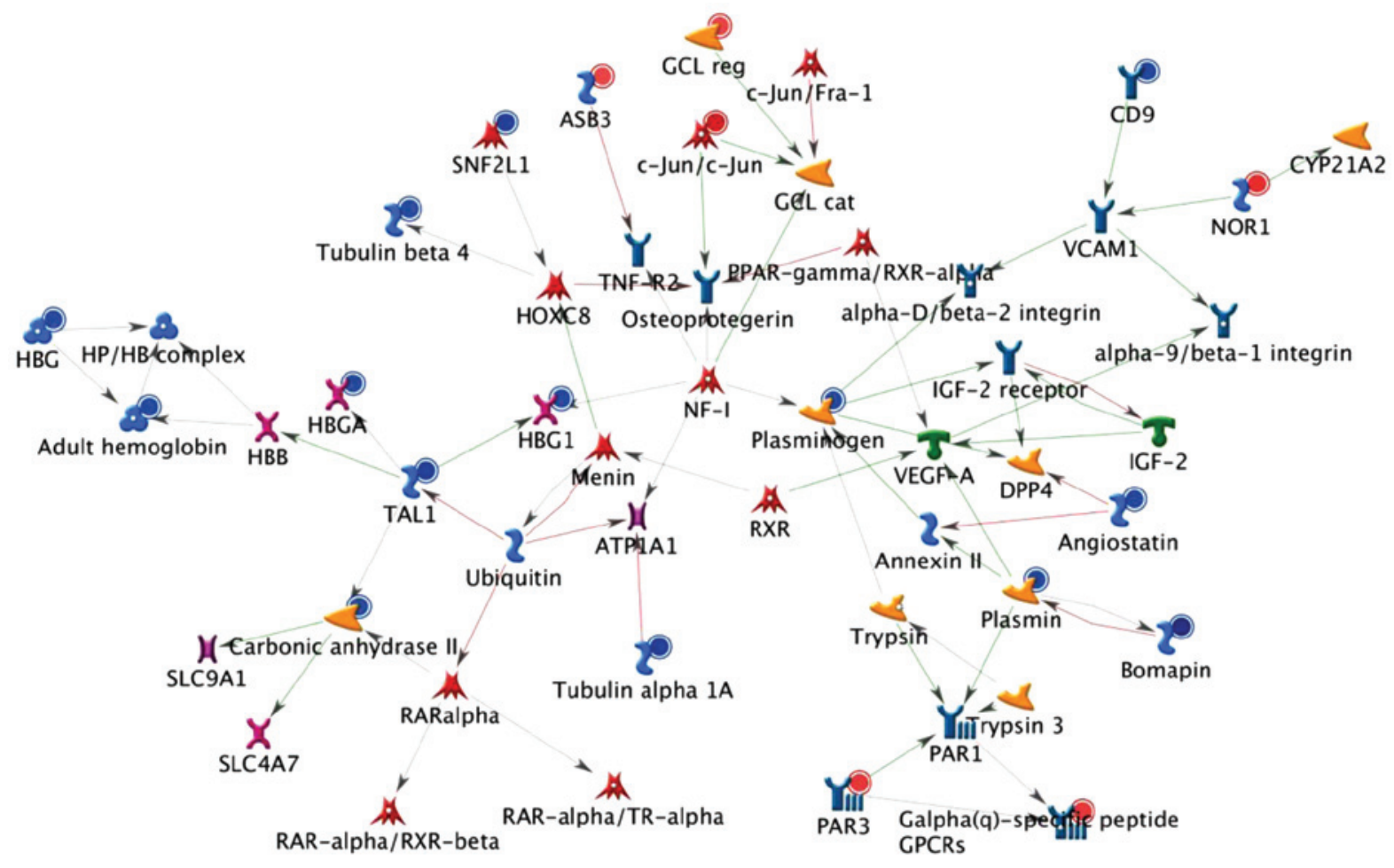

Figure 2. Second scored (by the number of pathways) AN network, as determined using GeneGo_cat_FC2 analysis. Thick cyan lines indicate the fragments of canonical pathways. Upregulated genes are marked with red circles and downregulated genes are indicated with blue circles. FC, Fold Change 2.0; AN, Analyze Networks algorithm. 


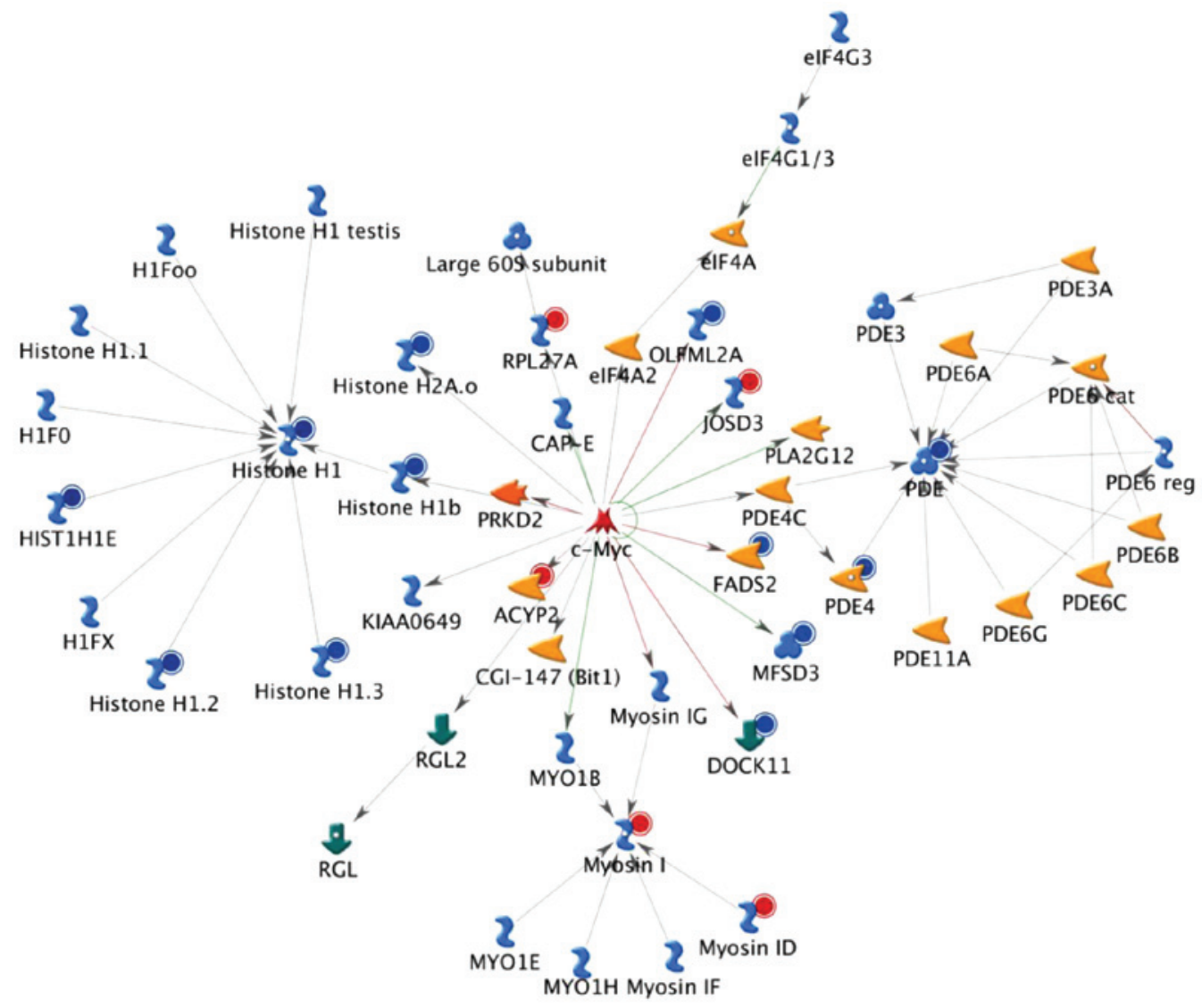

Figure 3. Third scored (by the number of pathways) AN network, as determined using GeneGo_cat_FC2 analysis. Thick cyan lines indicate the fragments of canonical pathways. Upregulated genes are marked with red circles and downregulated genes are indicated with blue circles. FC, Fold Change 2.0; AN, Analyze Networks algorithm.

GeneGo analysis. A GeneGo analysis program was used to analyze the CTD-treated NCI-H460 cells in order to determine the top scoring genes which were differentially expressed, as determined by the number of pathway networks involved. The results of the GeneGo analyses are shown in Figs. 1-3, which reveal the top, second and third scored genes by the number of pathways, respectively. Experimental data were used to generate maps of the pathway interactions and genes which were upregulated (indicated by red circles) and downregulated (indicated by blue circles) in H460 cells following treatment with CTD. It was indicated that these genes may also be involved in DNA damage, cell cycle arrest and apoptosis-associated responses in CTD-treated H460 cells.

\section{Discussion}

CTD has been reported to have cytotoxic effects in numerous different types of cancer cell (8-15). The results of previous studies have also demonstrated that CTD-induced cell death occurred due to the induction of apoptosis in human lung cancer cells (data not shown) (23). However, the effects of CTD on gene expression in cancer cells have remained to be elucdiated. To the best of our knowledge, the present study was the first to report on the effects of CTD on gene expression in H460 cells. Therefore, the present study not only advanced the understanding of the differential gene expression following treatment with CTD in lung cancer cells, but may additionally provide several potential biomarkers for use as future therapeutic clinical targets for the treatment of lung cancer.

It has been well documented that the tumor microenvironment, which contains matrix proteins, stromal cells and associated secreted molecules, including cytokines and associated genes, which may be used as targets of cancer therapeutic drugs (24-26). Therefore, an increasing number of studies focus on elucidating the tumor microenvironment and associated gene expression in order to determine potential novel therapeutic agents for treating cancer patients (27). Over the past decade, there have been numerous clinical trials of treatments for lung cancer patients, including adjuvant chemotherapy trials and neo-adjuvant chemotherapy trials (28-30); however, the results of these trials have not yet provided a successful, effective treatment for lung cancer. Numerous studies have demonstrated that chemotherapeutics may result in cell death through DNA damage, cell cycle arrest and the induction of apoptosis $(31,32)$. In the present study, H460 cells were treated with CTD and incubated in 12-well plates, and their RNA was then isolated in order to determine which genes exhibited altered expression following treatment with CTD. The results revealed that CTD effected the upregulation and downregulation, respectively, of the expression of certain genes which are known to be associated with DNA damage, cell cycle progression and apoptosis in H460 cells.

In order to further elucidate the molecular signaling pathways associated with altered gene expression in H460 cells following exposure to CTD, GeneGo Process Networks were 
used in the present study in order to analyze the altered gene expression results of the microarray, in order to determine the possible signaling pathways involved. Based on GeneGo pathway and canonical pathway maps, which represent a set of 650 signaling and metabolic maps covering human biology (signaling and metabolism) in a comprehensive way. A preset network of protein interaction characteristics for the process was used for each process, and the experimental data were mapped regarding the specific process. The obtained hypothetical molecular signaling pathways indicated that CTD affects numerous associated signaling pathways, indicated by the involvement of the differentially expressed genes in the network of the respective the signaling pathways. The gene content of the uploaded files was used as the input list for the generation of biological networks using the Analyze Networks algorithm with default settings. This is a variant of the shortest paths algorithm, with main parameters of relative enrichment with the uploaded data, and relative saturation of the networks with canonical pathways. The network provides data listing interacting proteins. In this workflow the network is prioritized based on the number of fragments of canonical pathways on the network.

In conclusion, the results of the present study revealed that treatment with CTD induced the upregulation and downregulation of numerous genes in H460 cells. In addition, these differentially expressed genes were associated with DNA damage, cell cycle progression and apoptotic cell death in human lung cancer H460 cells. The present study also revealed possible signaling pathways, which may provide more information on the possible mechanism of CTD in H460 cells; however, further studies are required.

\section{Acknowledgements}

The present study was supported by a grant from China Medical University [grant no. MU 101-AWARD-03(1/2); Taichung, Taiwan].

\section{References}

1. Bilello KS, Murin S and Matthay RA: Epidemiology, etiology, and prevention of lung cancer. Clin Chest Med 23: 1-25, 2002.

2. Parkin DM, Bray F, Ferlay J and Pisani P: Global cancer statistics, 2002. CA Cancer J Clin 55: 74-108, 2005.

3. Zhang P, Gao WY, Turner S and Ducatman BS: Gleevec (STI-571) inhibits lung cancer cell growth (A549) and potentiates the cisplatin effect in vitro. Mol Cancer 2: 1, 2003.

4. Midthun DE and Jett JR: Chemotherapy for advanced lung cancer. When to expect a response. Postgrad Med 101: 187-194, 1997.

5. Stewart DJ: Tumor and host factors that may limit efficacy of chemotherapy in non-small cell and small cell lung cancer. Crit Rev Oncol Hematol 75: 173-234, 2010.

6. Chansky K, Sculier JP, Crowley JJ, et al; International Staging Committee and Participating Institutions: The International Association for the Study of Lung Cancer Staging Project: prognostic factors and pathologic TNM stage in surgically managed non-small cell lung cancer. J Thorac Oncol 4: 792-801, 2009.

7. Zhang W, Ma YZ, Song L, Wang CH, Qi TG and Shao GR: Effect of cantharidins in chemotherapy for hepatoma: A retrospective cohort study. Am J Chin Med 42: 561-567, 2014.

8. Dorn DC, Kou CA, Png KJ and Moore MA: The effect of cantharidins on leukemic stem cells. Int J Cancer 124: 2186-2199, 2009.

9. Huh JE, Kang KS, Chae C, Kim HM, Ahn KS and Kim SH: Roles of p38 and JNK mitogen-activated protein kinase pathways during cantharidin-induced apoptosis in U937 cells. Biochem Pharmacol 67: 1811-1818, 2004.
10. Li W, Xie L, Chen Z, et al: Cantharidin, a potent and selective PP2A inhibitor, induces an oxidative stress-independent growth inhibition of pancreatic cancer cells through G2/M cell-cycle arrest and apoptosis. Cancer Sci 101: 1226-1233, 2010.

11. Yeh CB, Su CJ, Hwang JM and Chou MC: Therapeutic effects of cantharidin analogues without bridging ether oxygen on human hepatocellular carcinoma cells. Eur J Med Chem 45: 3981-3985, 2010

12. Chang C, Zhu YQ, Mei JJ, Liu SQ and Luo J: Involvement of mitochondrial pathway in NCTD-induced cytotoxicity in human hepG2 cells. J Exp Clin Cancer Res 29: 145, 2010.

13. Huang WW, Ko SW, Tsai HY, et al: Cantharidin induces G2/M phase arrest and apoptosis in human colorectal cancer colo 205 cells through inhibition of CDK1 activity and caspase-dependent signaling pathways. Int J Oncol 38: 1067-1073, 2011.

14. Zhang WD, Zhao HR, Yan Y, Wang XH, Zong ZH and Liu Y: Apoptosis induced by cantharidin in human pulmonary carcinoma cells A549 and its molecular mechanisms. Zhonghua Zhong Liu Za Zhi 27: 330-334, 2005 (In Chinese).

15. Kim JA, Kim Y, Kwon BM and Han DC: The natural compound cantharidin induces cancer cell death through inhibition of heat shock protein 70 (HSP70) and Bcl-2-associated athanogene domain 3 (BAG3) expression by blocking heat shock factor 1 (HSF1) binding to promoters. J Biol Chem 288: 28713-28726, 2013.

16. Osborne C, Wilson P and Tripathy D: Oncogenes and tumor suppressor genes in breast cancer: potential diagnostic and therapeutic applications. Oncologist 9: 361-377, 2004.

17. Heneghan HM, Miller N and Kerin MJ: MiRNAs as biomarkers and therapeutic targets in cancer. Curr Opin Pharmacol 10: 543-550, 2010.

18. Weinstein IB: Cancer. Addiction to oncogenes - the Achilles heal of cancer. Science 297: 63-64, 2002.

19. Luo J, Solimini NL and Elledge SJ: Principles of cancer therapy: oncogene and non-oncogene addiction. Cell 136: 823-837, 2009.

20. Solimini NL, Luo J and Elledge SJ: Non-oncogene addiction and the stress phenotype of cancer cells. Cell 130: 986-988, 2007.

21. Méndez M, Custodio A and Provencio M: New molecular targeted therapies for advanced non-small cell lung cancer. $\mathrm{J}$ Thorac Dis 3: 30-56, 2011.

22. Chang YM, Velmurugan BK, Kuo WW, et al: Inhibitory effect of alpinate Oxyphyllae fructus extracts on Ang II-induced cardiac pathological remodeling-related pathways in $\mathrm{H} 9 \mathrm{c} 2$ cardiomyoblast cells. BioMedicine 3: 148-152, 2013.

23. Hsia TC, Yu CC, Hsu SC, et al: Cantharidin induces apoptosis of H460 human lung cancer cells through mitochondria-dependent pathways. Int J Oncol 45: 245-254, 2014.

24. Ayala F, Dewar R, Kieran M and Kalluri R: Contribution of bone microenvironment to leukemogenesis and leukemia progression. Leukemia 23: 2233-2241, 2009.

25. Straussman R, Morikawa T, Shee K, et al: Tumour micro-environment elicits innate resistance to RAF inhibitors through HGF secretion. Nature 487: 500-504, 2012.

26. Wilson TR, Fridlyand J, Yan Y, et al: Widespread potential for growth-factor-driven resistance to anticancer kinase inhibitors. Nature 487: 505-509, 2012.

27. Moniri MR, Dai LJ and Warnock GL: The challenge of pancreatic cancer therapy and novel treatment strategy using engineered mesenchynmal stem cells. Cancer Gene Ther 21: 12-23, 2014

28. Pignon JP, Tribodet H, Sagliotti GV, et al; LACE Collaborative Group: Lung adjuvant cisplatin evaluation: A pooled analysis by the LACE Collaborative Group. J Clin Oncol 26: 3552-3559, 2008.

29. Pepe C, Hasan B, Winton TL, et al; National Cancer Institute of Canada and Intergroup Study FBR.10: Adjuvant vinorelbine and cisplatin in elderly patients: National Cancer Institute of Canada and Intergroup Study JBR.10. J Clin Oncol 25: 1553-1561, 2007.

30. Glynne-Jones R and Hoskin P: Neoadjuvant cisplatin chemotherapy before chemoradiation: A flawed paradigm? J Clin Oncol 25: 5281-5286, 2007.

31. Ricci MS and Zong WX: Chemotherapeutic approaches for targeting cell death pathways. Oncologist 11: 342-357, 2006.

32. Tan TT and White E: Therapeutic targeting of death pathways in cancer: Mechanisms for activating cell death in cancer cells. Adv Exp Med Biol 615: 81-104, 2008. 